\title{
Tumoral lesions of the bones of the hands - Pictorial essay
}

\author{
Subbarao Kakarla ${ }^{1, *}$
}

${ }^{1}$ KIMS Foundation and Research Centre, Minister Road, Secunderabad - 500003, Telangana, India

\begin{abstract}
All swellings of the fingers and hand are not neoplastic. The benign tumors of the bones of the hands and their radiographic manifestations have been described in the previous article. Conventional radiographs of the hands give a clue to the diagnosis of tumoral lesions of the bones. It is essential to correlate the radiological findings with clinical and laboratory data. Rarely it is necessary to go for advanced imaging like ultrasonography, computed tomography, magnetic resonance imaging and nuclide scans for a diagnosis.
\end{abstract}

Keywords: Tumor lesions of the bones; abnormalities of the bones; bones of the hands; infective and metabolic disorders

*Corresponding author: Prof. Kakarla Subbarao, MS, D.Sc. (HON), FRCR, FACR, FICP, FSASMA, FCCP, FICR, FCGP, Chairman, KIMS Foundation and Research Centre, Minister Road, Secunderabad 500003, Telangana, India. Email: subbaraokakarla25@gmail.com

Received 22 May 2018; Accepted 05 June 2018; Published 13 June 2018

Citation: Kakarla S. Tumoral lesions of the bones of the hands - Pictorial essay. J Med Sci Res. 2018; 6(3): 86-92. DOI: http:// dx.doi.org/10.17727/JMSR.2018/6-15

Copyright: (c) 2018 Kakarla S. Published by KIMS Foundation and Research Center. This is an open-access article distributed under the terms of the Creative Commons Attribution License, which permits unrestricted use, distribution, and reproduction in any medium, provided the original author and source are credited.

\section{Introduction}

As described earlier [1], 27 bones exist in each wrist and hand. The classification of tumor like lesions of the bones of the hand in wrist is mentioned in table 1 . The radiographic features of various lesions are described in detail [2-4].

Table 1: Tumor like lesions.

Developmental:
$\quad>\quad$ Fibrous dysplasia
$>\quad$ Neurofibromatosis
$>\quad$ Tuberous sclerosis
$>\quad$ Macrodystrophia lipomatosa
$>\quad$ Proteus syndrome
$>\quad$ Melorheostosis
Infections:
$>\quad$ Osteomyelitis - Bacterial, fungal
$>\quad$ Spina ventosa of tuberculosis
Granulomas:
$>\quad$ Foreign body granuloma
$>\quad$ Epidermoid cyst of the distal phalanx




\section{Endocrinal \& metabolic:}

$>$ Brown tumor - Hyperparathyroidism

$>$ Gout and pseudo gout

$>$ Paget's

Miscellaneous:

$>$ Giant cell reparative granuloma

$>$ Bizarreparaostealosteochondromatous proliferation (Nora's lesion)

$>\quad$ Giant cell tumor of the tendon sheath (pigmented villonodular synovitis pvns)

\section{Discussion of the radiological features}

Tumor like lesions of the bones of the hand are more frequent than benign tumors. Some of these are focal and many of them are systemic in etiology. Systemic lesions may involve a single or multiple bones. The study of soft tissues is quite important in determining the nature of the lesion. Imaging characteristics of each of these entities are described pictorially.

\section{Imaging features of lesions of developmental origin}

\section{Fibrous dysplasia}

It is a developmental error and generally manifests before puberty. It may be monostotic, polyostotic or part of Albright and mazabraud syndromes [5]. The focal lesion is generally an expanding lytic area with a ground glass appearance (Figure 1a). A well defined border exists with infrequent mineralization of the matrix. Polyostotic fibrous dysplasia involves more than one bone and may be bilateral but not symmetrical (Figure 1b, c). Deformities of the fingers may be noted in but pathological fractures are rare. Similar features are noted in hand bones of Albright's and mazabraud syndromes.

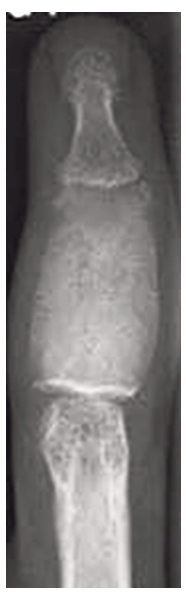

Figure 1a: Monostotic fibrous dysplasia of middle phalanx (Note the ground-glass matrix).

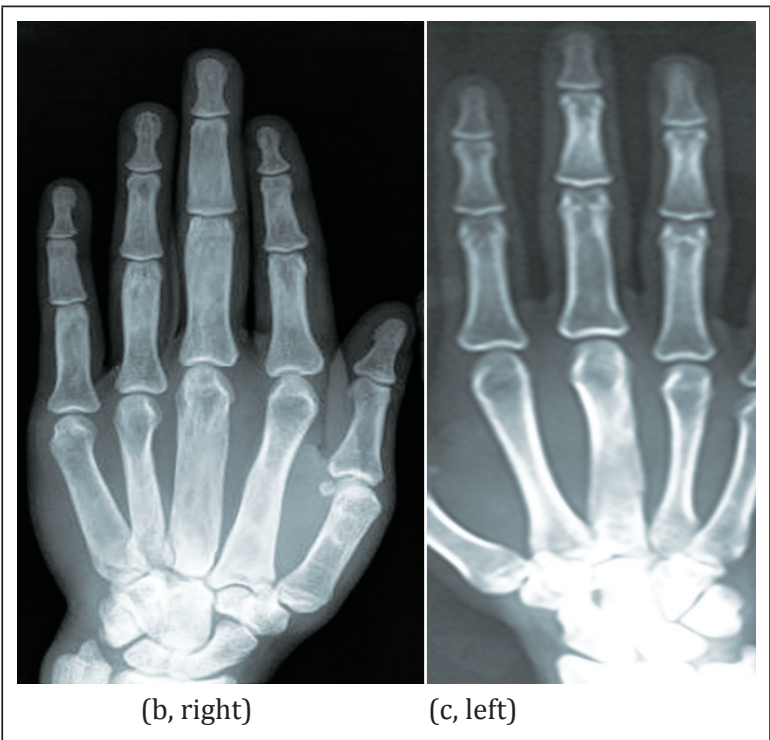

Figure 1b, c: Polyostotic fibrous dysplasia (Note the ground glass appearance of the bones of the right $3^{\text {rd }}$ finger and $3^{\text {rd }}$ metacarpal of left hand).

\section{Neurofibromatosis (NF)}

It is a genetic disorder with benign neurofibromas associated with messenchymal dysplasia of the bones. There are several types of neurofibromatosis including NF1, NF2 up to NF7. Isolated schwannomas are also encountered. NF1 is also known as von Recklinghausen disease and involves many systems. This is the most common neurocutaneous disorder and belongs to the group of phacomatosis. It manifests as soft tissue swellings focal or diffuse in nature deforming the fingers. Osseous defects, deformities and growth defects are also noted (Figure 2). In messenchymal dysplasia involving the bones, neurofibroma at the site may not be present [6].

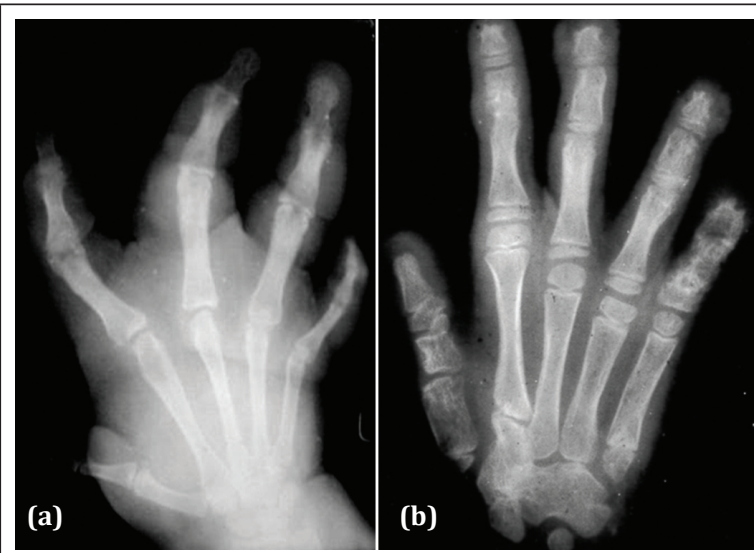

Figure 2: Neurofibromatosis 1; (a) adult with cutaneous plexiform neurofibromata, (b) child with bony defects and deformities due to associated messenchymal dysplasia. 


\section{Tuberous sclerosis (epiloia)}

Clinically, a triad of symptoms exist including adenoma sebaceum, epilepsy and mental retardation. It is also known as tuberous sclerosis complex or Bourneville disease. It is a neurocutaneous disorder (phakomatosis) characterised by the development of multiple benign tumours of the embryonic ectoderm. The musculoskeletal lesions of the hands include sclerotic bone lesions, 40-66\%, periosteal new bone formation, cortical pitting and cystic lesions (Figure3).

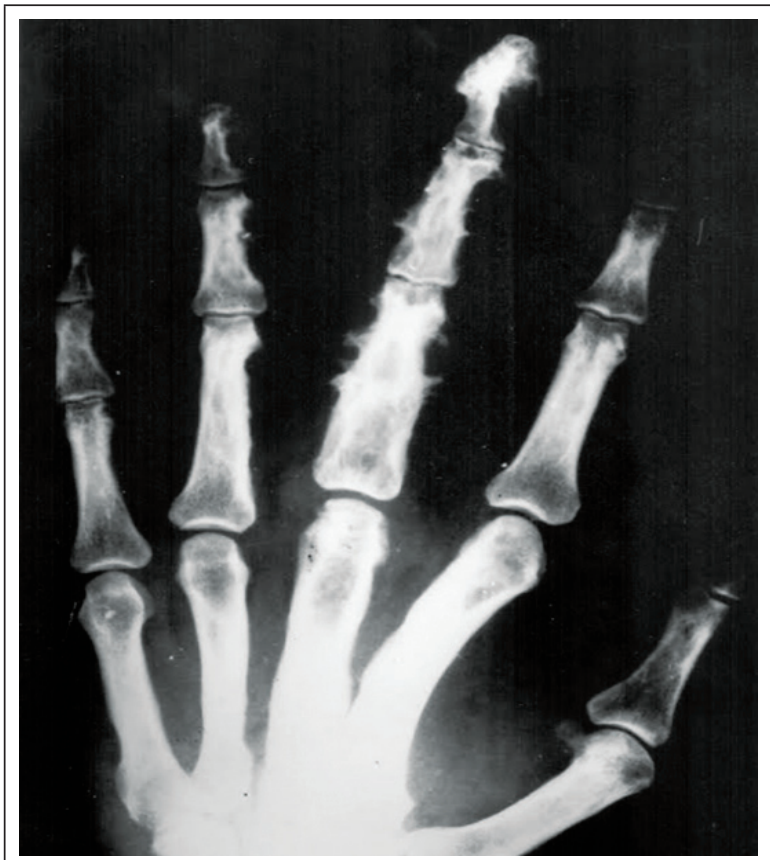

Figure 3: Tuberous sclerosis (note the cortical pitting and sclerosis of the bones).

\section{Macrodystrophia lipomatosa}

It is a rare form of localised gigantism. This term includes macrodactyly, megalodactyly, digital gigantism, macromelia, partial acromegaly, macrosomia, and limited gigantism. Most frequent occurrence in the hand is in the distribution of the median nerve [7]. The findings include a predominately distal involvement, enlargement of the phalanges and soft tissue elements of the digit with lucency of the soft tissues due to fat (Figure 4).

\section{Proteus syndrome}

Proteus syndrome is a rare congenital disorder characterized by overgrowth of the bones, skin, and other tissues. Organs and tissues affected by the disease grow out of proportion to the rest of the body.

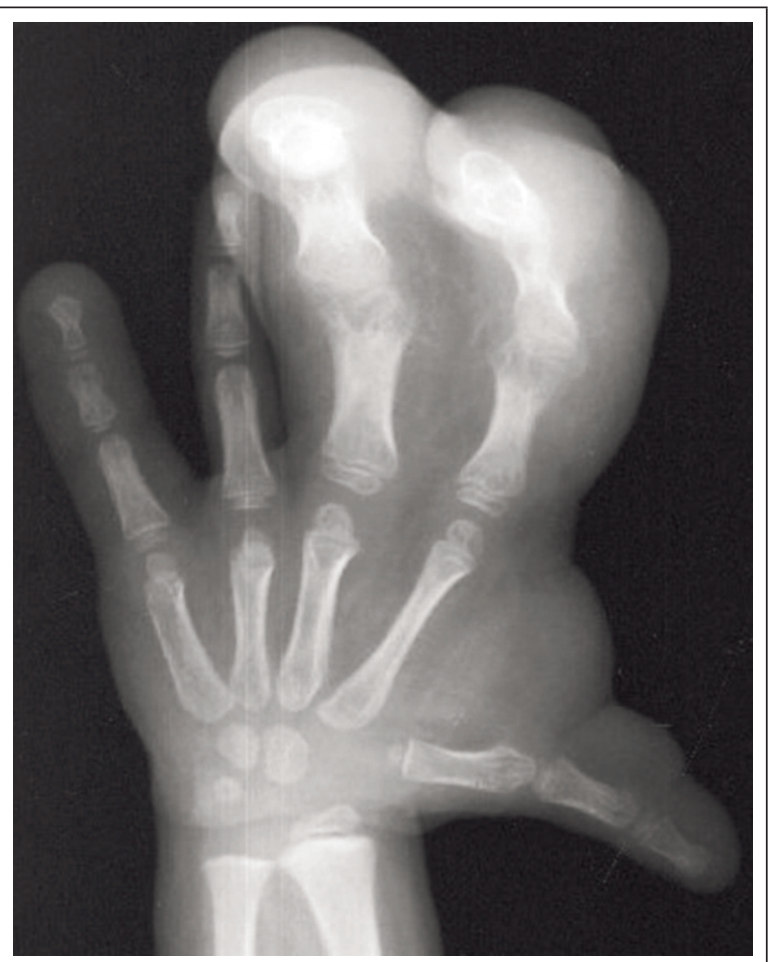

Figure 4: Macrodystrophia lipomatosa (Note the large soft tissue component).

The overgrowth is usually asymmetric and affects the right and left sides of the body differently. Radiologically, the bones are enlarged with exostosis like new bone formation around the joints (Figure 5). Macrodystrophia lipomatosa may be considered a part of proteus syndrome. The differentiation between these two include positive family history in proteus syndrome and presence of palmar and plantar cerebroid thickening [8].

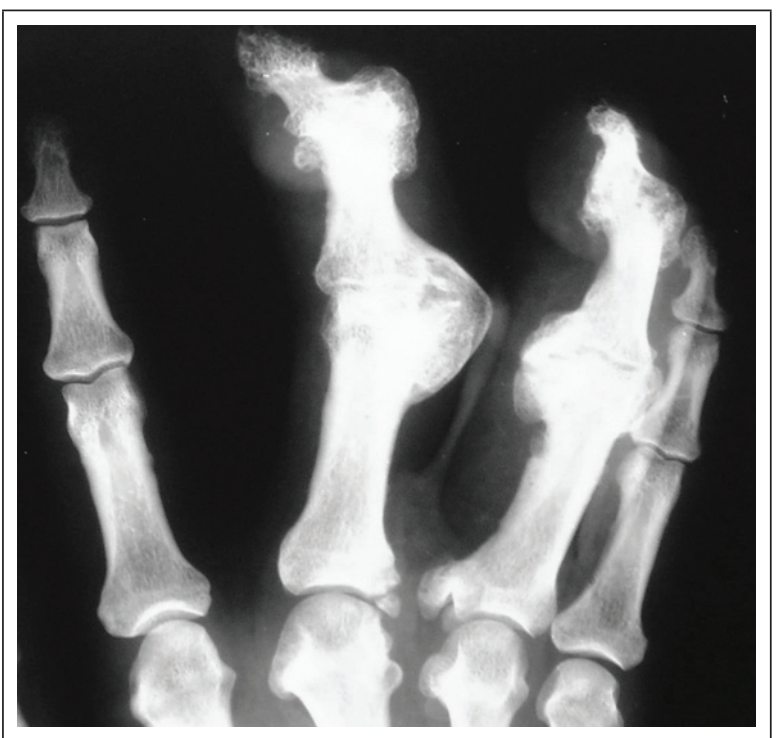

Figure 5: Proteus syndrome. 


\section{Melorheostosis}

It is a form of sclerosing dysplsia with flowing hyperostosis and segmental distribution corresponding to one or more sclerotomes [9]. Radiologically, the cortical deposits have been likend to candle wax flowing down the effected bone. Heterotopic bone may be seen in soft tissues (Figure $6)$.

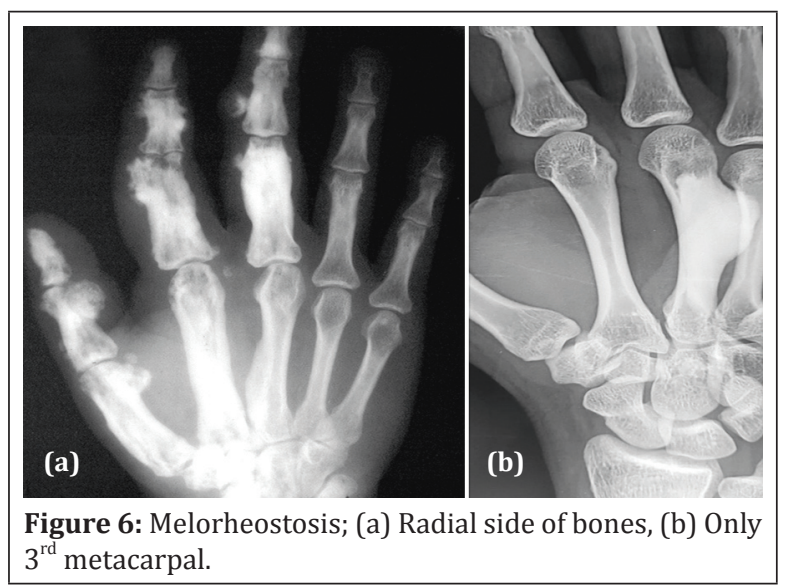

\section{Infections}

\section{Osteomyelitis}

Pyogenic osteomyelitis involving the hand bones is one of the commonly observed entity simulating a neoplasm. It may be in acute, subacute or chronic stage. Radiologically, a spectrum of findings exist depending upon the stage. In general, lytic areas with reactive new bone and periosteal reaction are noted (Figure 7a). Osteomyelitis is also noted in fungal and leprotic infections [9]. The characteristic radiological findings of fungal infection include diffuse sclerosis, spiculated periosteal reaction and lack of major sequestra (Figure 7b). In leprotic infection, multiple bones are involved with lytic changes. No new bone formation or periosteal reaction is noted unless there is secondary infection. Acroosteolysis is common (Figure 7c).

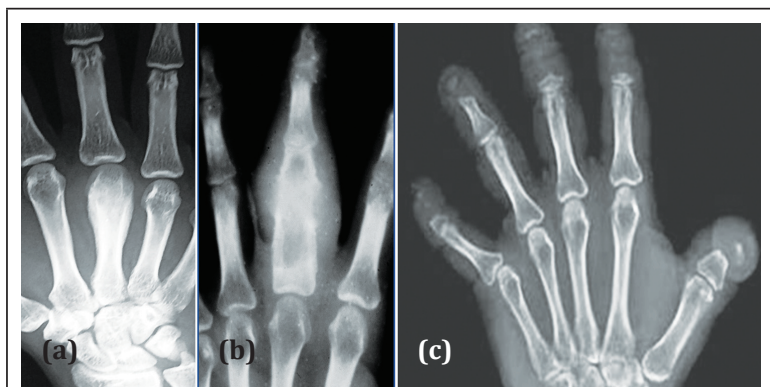

Figure 7: (a) Pyogenic osteomyelitis, (b) Actinomycosis, (c) Leprosy.

\section{Tuberculosis}

Spina ventosa is a common manifestation of digits of the hand particularly in children. It is a form of cystic tuberculosis with expansion of the bone. Very little periosteal reaction is noted. May involve more than one bone (Figure 8).

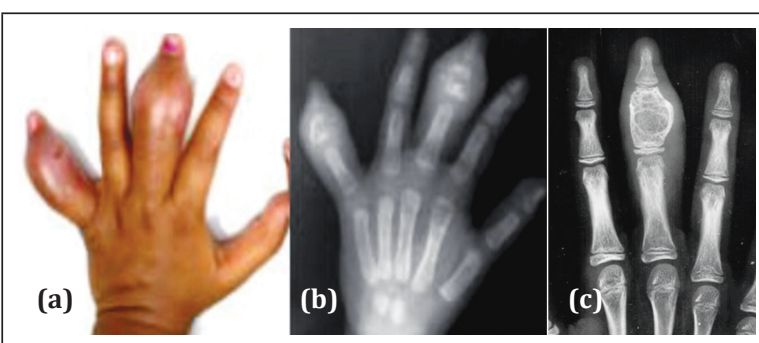

Figure 8: Spina Ventosa - TB; (a) clinical, (b) multiple bones, (c) single phalanx.

\section{Granulomas}

\section{Foreign body granuloma}

Since hands play a major role in the daily activities, foreign bodies are commonly noted in the soft tissues. Some of them are opaque and some lucent. This foreign body may penetrate the bone and invoke a lytic lesion (Figure 9).

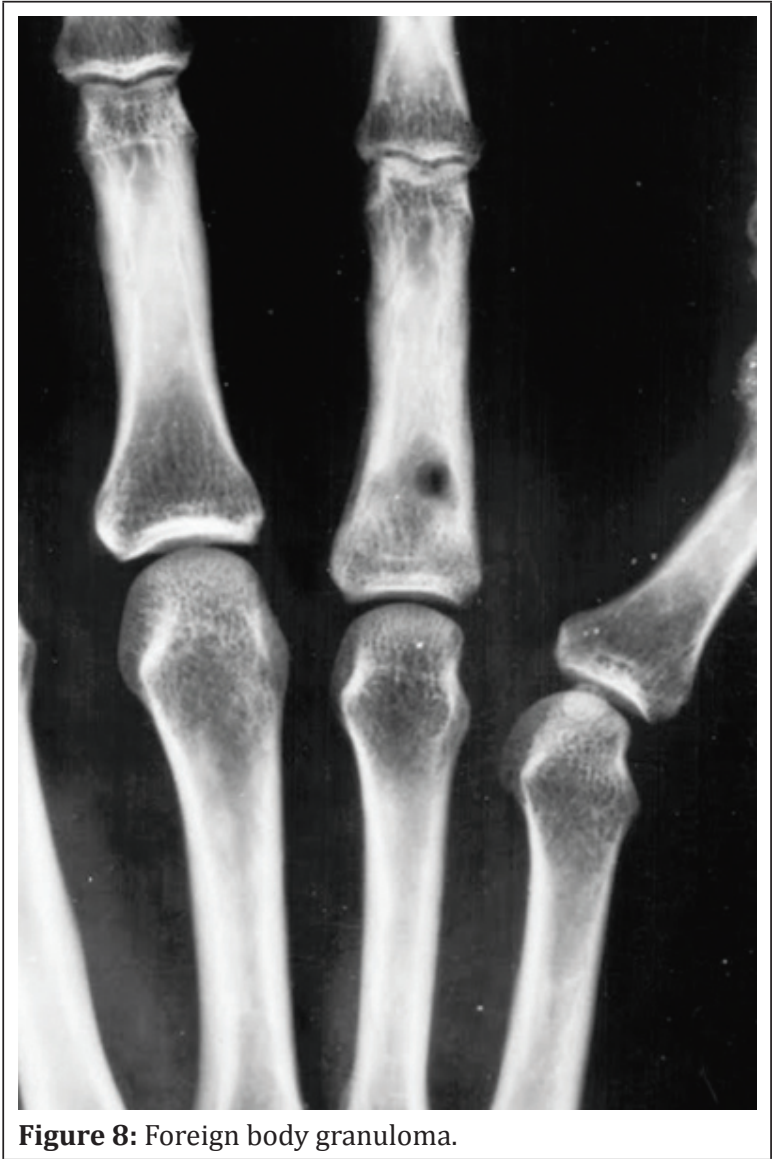




\section{Epidermoid cyst of the distal phalanx}

These are pseudo tumors, most probably of traumatic origin. Radiologically, it is a lucent lesion with well defined sclerotic margin. Associated soft tissue swelling doesn't show any mineralisation. Typically it occurs in the distal phalanx (Figure 9).

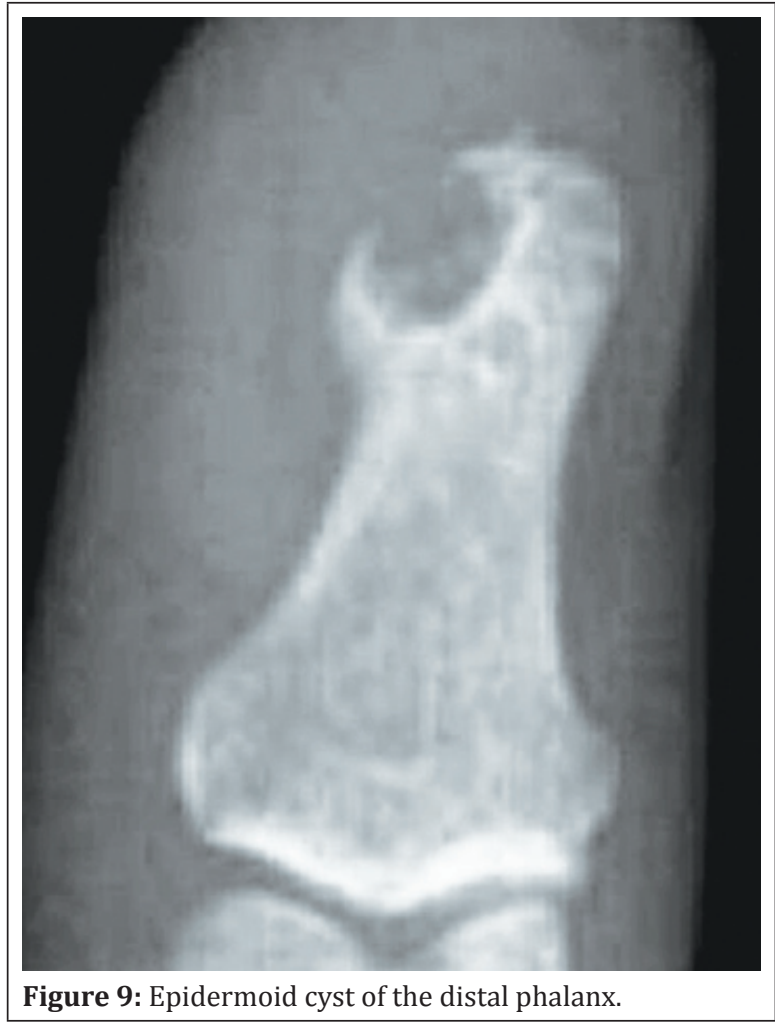

\section{Endocrinal and metabolic}

\section{Brown tumor - Hyperparathyroidism}

In primary and secondary hyperparathyroidism, absorption of the bone is common and one of the focal manifestations is brown tumor [9]. Radiologically, it is a benign lytic lesion with no reactive sclerosis or periosteal reaction. The other phalanges may show subperiosteal resorption and resorption of the tufts which give a clue to the diagnosis (Figure 10).

\section{Gout and pseudo gout}

Among the crystal deposition disorders, gout and pseudo gout are relatively common. Monosodium urate crystals characterise gout. Radiologically, first toe is the common site but hands and wrists also can be involved. Eccentric erosions with overhanging edges associated with a soft tissue swelling are the common manifestations noted in the joints and is often asymmetrical (Figure 11a, b).

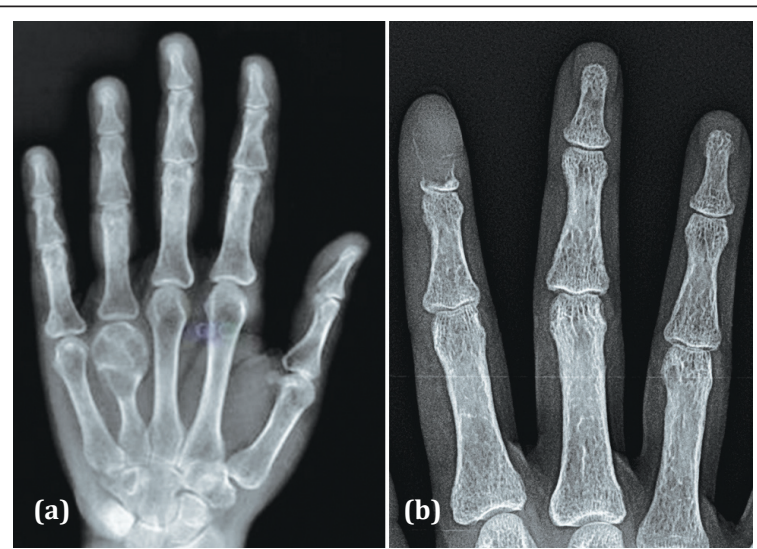

Figure 10: Brown Tumor of hyperparathyroidism; (a) brown tumor involving the head of the $4^{\text {th }}$ metacarpal, (b) distal phalanx of index finger.

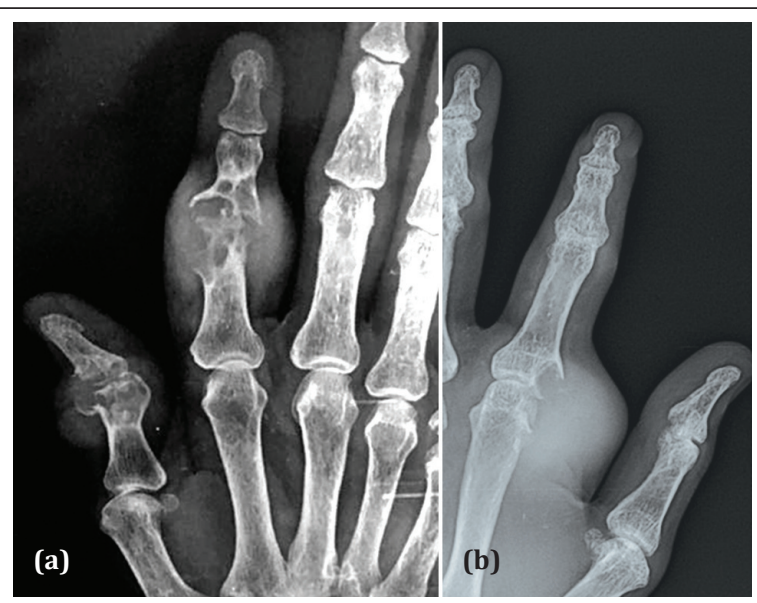

Figure 11a, b: Gout; note the erosions and soft tissue swellings.

Pseudo gout may clinically resemble gout. Calcium pyrophosphate dihadrate crystals are deposited in the articular cartilages, synovium and other paraarticular structures [10]. This may lead to degenerative changes in the joints of the hand and wrist. Radiologically, calcifications of the articular cartilages and paraarticular structures are noted along with degenerative changes (Figure 12).

\section{Paget's}

Paget disease is rarely encountered in India and any bone of the skeleton may be involved. It may be monostotic or polyostotic. Paget involving the bones of the hand is rare. It may be encountered in three stages: lytic, sclerotic or mixed. The bone involved is bigger, brighter and the process extends all the way to articular margin [11]. It may be purely lytic or mixed with sclerosis and lytic areas. The sclerotic form may simulate a neoplasm (Figure 13). 


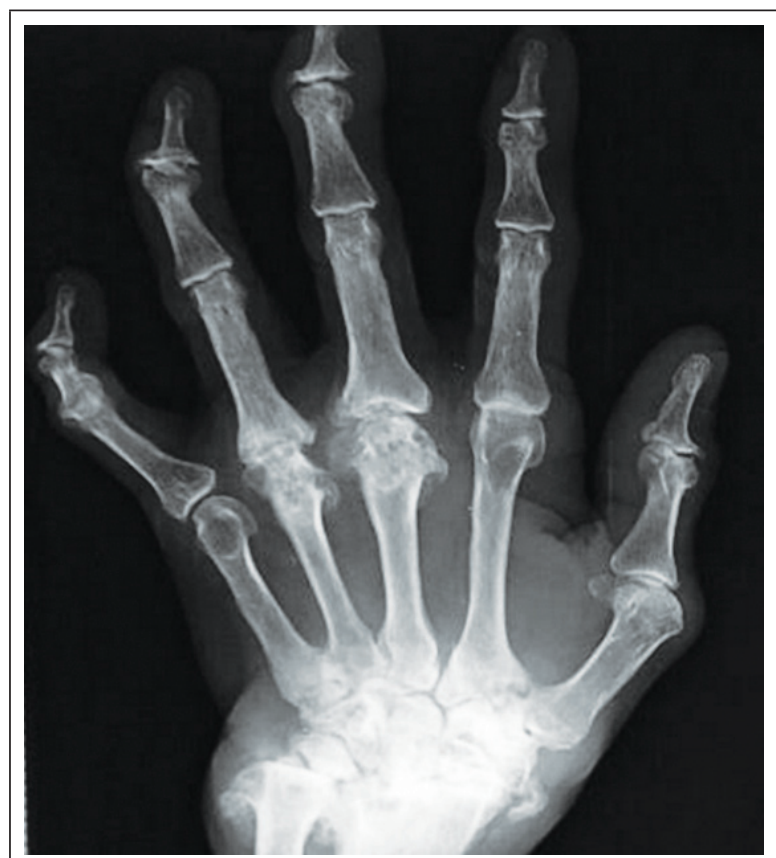

Figure 12: $62 \mathrm{M}$, CPPD (calcium pyrophosphate dehydrate crystal deposition disease)- pseudo gout.

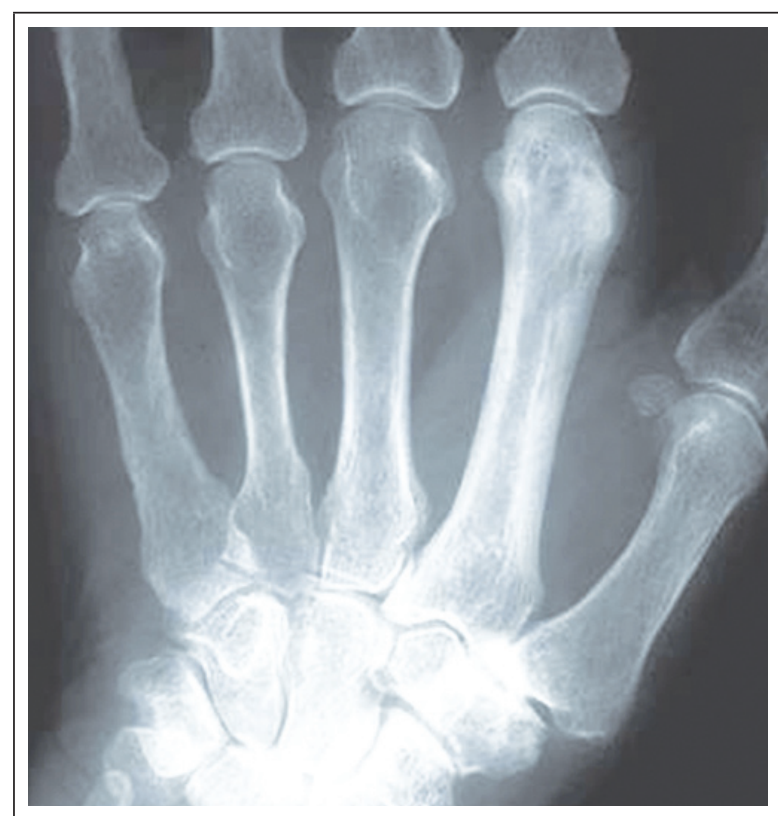

Figure 13: Paget disease involving the second metacarpal showing enlargement and sclerosis.

\section{Miscellaneous}

\section{Giant cell reparative granuloma}

Although this is commonly encountered in the jaws, may also be noted in the bones of the hand. Radiologically, an oval or round osteolytic lesion is noted with expansion and thinning of the cortex [12]. This appearance simulates giant cell tumor (Figure 14).

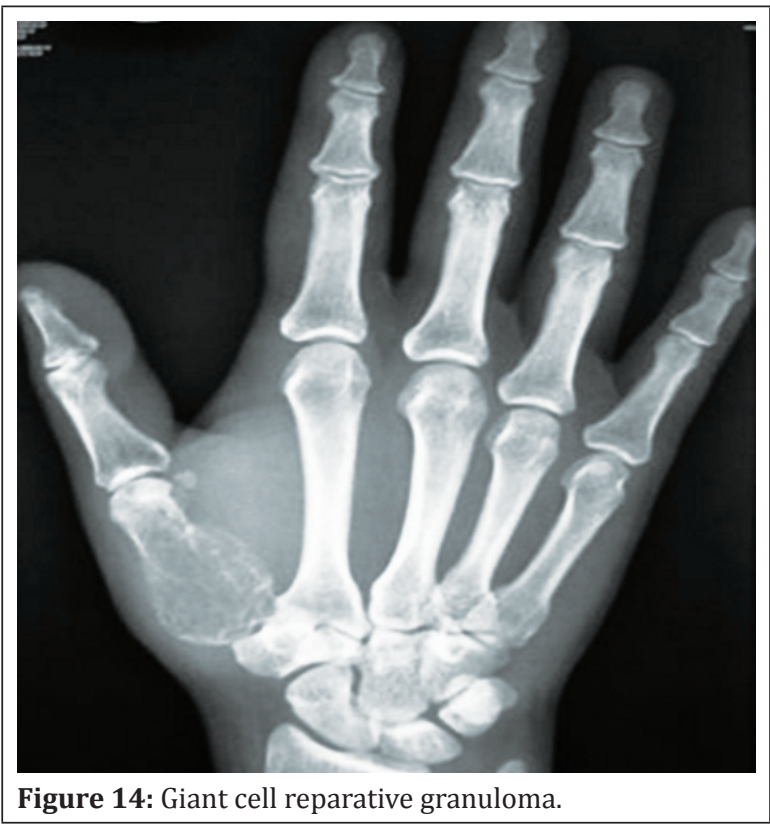

\section{Bizarre paraosteal osteochondromatous proliferation (Nora's lesion)}

Bizarre parosteal osteochondromatous proliferation (BPOP) is a rare lesion and has been described by Nora. The lesion is an exophytic outgrowth from the cortical surface consisting of bone, cartilage and fibrous tissue. It usually affects the proximal and middle phalanges, and the metacarpal or metatarsal bones $[13,14]$. The bones of the hand are the common site. The lesion affects patients of any age, but most are in their 20s and 30s with no sex predilection. This lesion of the bone is often mistaken for a malignant processes because of the high frequency of recurrence after excision. Radiologically, an outgrowth of bone is noted without any medullary involvement (Figure 15). Histologically, a cartilage cap may be seen.

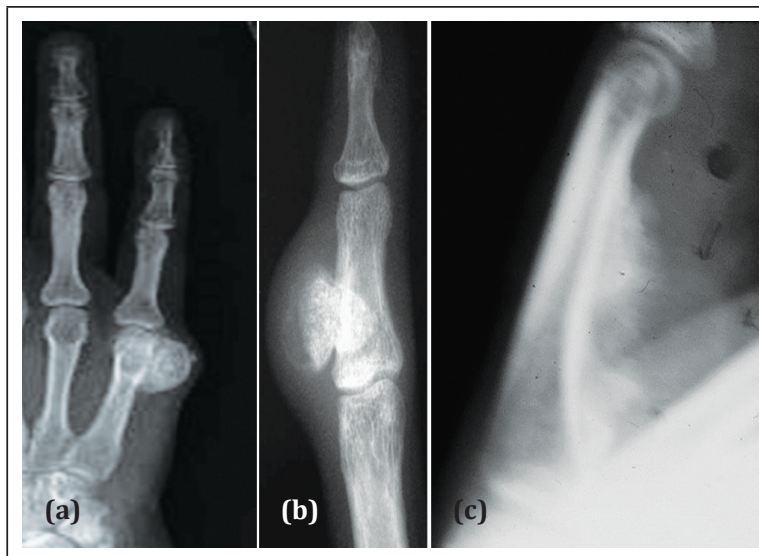

Figure 15: Bizarre parasteal osteochondromatous proliferation (Nora lesion); (a) Metacarpal head, (b, c) phalanges of the hand. 
Giant cell tumor of the tendon sheath (pigmented villonodular synovitis - pvns)

This is due to proliferation of the synovium of the joint or tendon sheath. It can be focal or diffuse. Radiologically, a nodular soft tissue swelling is noted para-articularly or along the tendon sheath. In several instances the adjacent bone may be eroded showing a lucent defect with sclerotic margin (Figure 16).

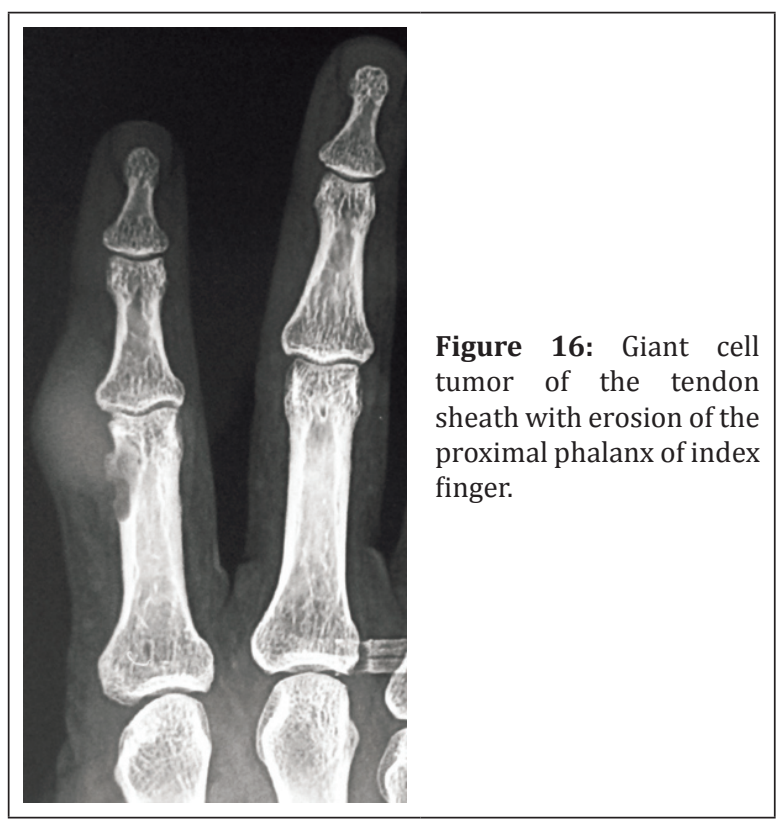

\section{Conclusion}

All the swellings of the bones of the hand are not true neoplasms. Radiology plays a major role in differentiating neoplastic bone lesions from tumor like lesions. Conventional radiology is adequate in most of the situations. Radiographic manifestation of each entity which include lesions of developmental, infective, endocrinal and metabolic and miscellaneous group are described pictorially.

\section{Acknowledgements}

NIMS (Hyderabad), KIMS (Secunderabad) and KREST Museum (Hyderabad).

\section{Conflicts of interest}

Author declares no conflicts interest.

\section{References}

[1] Kakarla S. Benign tumors of the bones of the hands. JMSR. 2018; 6(2):49-58.

[2] Plate AM, Lee SJ, Steiner G, Posner MA. Tumor like lesions and benign tumors of the hand and wrist. J Am Acad Orthop Surg. 2003; 11(2):129-141.
[3] Ostrowski ML, Spjut HJ. Lesions of the bones of the hands and feet. Am J Surg Pathol. 1997; 21(6):676-690.

[4] Ahmed O, Moore DD, StacyGS. Imaging diagnosis of solitary tumors of the phalanges and metacarpals of the hand. AJR Am J Roentgenol. 2015; 205(1):106-115.

[5] Kakarla S. Imaging in fibrous dysplasia. JMSR. 2013; 1(2):7481.

[6] Kakarla S. Neurofibromatosis-Imaging spectrum. Proceedings of KFRC. 2012; 1(2):11-20.

[7] Murphey MD, Carroll JF, Flemming DJ, Pope TL, Gannon FH, et al. From the archives of the AFIP: Benign musculoskeletal lipomatous lesions. Radiographics. 2004; 24(5):14331466.

[8] Jamis-Dow CA, Turner J, Biesecker LG, Choyke PL. Radiologic manifestations of proteus syndrome. Radiographics. 24(4):1051-1068.

[9] Kakarla S. Tumoral lesions of bone. JMSR. 2014; 2(3):161168.

[10] Kakarla S. Radiology of crystal arthropathies. JMSR. 2015; 3(4):187-191.

[11] Kakarla S. Paget disease of skeleton - Pictorial essay. JMSR. 2014; 2(1):34-40.

[12] Lorenzo JC, Dorfman HD. Giant-cell reparative granuloma of short tubular bones of the hands and feet. Am J Surg Pathol. 1980; 4(6):551-563.

[13] Gruber G, Giessauf C, Leithner A, Zacherl M, Clar H, et al. Bizarre parosteal osteochondromatous proliferation (Nora lesion): A report of 3 cases and a review of the literature. Can J Surg. 2008; 51(6):486-489.

[14] Joseph J, Ritchie D, MacDuff E, Mahendra A. Bizarre parosteal osteochondromatous proliferation: A locally aggressive benign tumor. $\mathrm{C}$. 